\title{
Relations, Risks, Portfolio Theory and Key Natural Laws in Economics
}

\author{
Yi-Jang $\mathrm{Yu}^{1}$ \\ ${ }^{1}$ Department of Economics, Ming-Chuan University, Taoyuan, Taiwan, R. O. C. \\ Correspondence: Yi-Jang Yu, Department of Economics, Ming-Chuan University, 5 Der Ming Rd., Gui Shan \\ District, Taoyuan County 333, Taiwan, R. O. C. E-mail: yjyu@mail.mcu.edu.tw
}

Received: July 2, 2014

doi:10.5430/rwe.v5n2p143

\author{
Accepted: August 11, $2014 \quad$ Online Published: August 30, 2014 \\ URL: http://dx.doi.org/10.5430/rwe.v5n2p143
}

\begin{abstract}
Economics can be more practical if relationship and risk, as well as scarcity and abundance, are considered key elements in economic analyses. By applying relations and risks through MPT, the long and difficult task of introducing an appropriate economic environment into a balanced pricing model can become a reality. Accordingly, both individual and social rationality can function independently and a strong balancing effect can be established without any governmental intervention in the pricing model. Alternatively, a more philosophical approach is required for revealing the content of key natural laws in macroeconomics. Several ancient conceptual schemes and doctrines that are well known among Chinese people are suggested to serve this purpose. The conclusion from this study is that the evolution of the global economy still complies with key natural laws in macroeconomics; however, severe violation of key natural laws in microeconomics requires immediate remedy.
\end{abstract}

Keywords: relations, risks, portfolio theory, natural laws

\section{Introduction}

Resource scarcity is currently still considered by mainstream economic textbooks as the origin of all economic problems. Before the demand of subsistence goods can be effectively satisfied, the primary economic concern of a society must focus on the life-threatening risk of scarcity. However, after the industrial revolution and rapid development of scales of economy, severe economic problems around the world have been primarily caused not by scarcity, but by abundance (Galbraith, 1960). Meanwhile, following an extended period of over-consumption, the international community has incurred a large number of external costs which, in turn, has severely damaged all ecological, economic and social environments. Moreover, policies addressing the risk of life-threatening or economic failure are typically contradictory, thereby increasing the difficulty of pursuing economic development.

Consumption must have a purpose, be it individual, national, immediate, or future demands. However, the main origin of individual and national demand is individual and social rationality, respectively. Both are necessary elements for effectively promoting economic development, but how to reconcile them has long been a focus of debate between capitalists and socialists.

A unique feature of classical economics is the belief in natural order and laws. Therefore, if the key natural laws, in both microeconomics and macroeconomics, can be determined, whether the current global economic environment operates under them is absolutely of interest.

This study explained first that, in addition to scarcity or abundance, key elements in economic analyses also involve relations and risks. By combining relation, risk, and Markowitz's portfolio theory (MPT) as the most applicable analytical tool, the pricing mechanism in general can be constructed with a strong balancing function and pricing stability for serving key natural laws in microeconomics. Alternatively, a more philosophical approach is required for revealing the content of key natural laws in macroeconomics. Several ancient conceptual schemes and doctrines that are well known among Chinese people are suggested in this study to serve this purpose. The conclusion from this study is that the evolution of the global economy still complies with key natural laws in macroeconomics. However, severe violation of key natural laws in microeconomics requires immediate remedy.

\section{Environmental Relations}

Relationships are a key element in economic analyses. (Note 1) A market can only be realized with at least a seller and a buyer; the relationship between both sides is clearly crucial in making a deal. Necessary exclusivity and 
imperfection in consumption invariably affects people, immediately or eventually. (Note 2)

Regarding chemical relationships, productivity can be increased substantially through effective cooperation among well-designed divisions of labour. Risk diversification, based on MPT, is an example when discussing physical relationships.

A relationship is not studied economically unless it has certain economic implications. An example is scarcity, in that it cannot illicit the discontent of future generations; however, over consuming available resources and damaging the environment clearly will. By disregarding the necessity of endogenising external costs, the pricing approach of mainstream economics is intuitively constructed based on individual rationality. (Note 3) Hence, it disregards matters such as the greenhouse effect and financial turmoil.

Environmental relations have long been ignored in economic analyses especially after introducing the concept of external costs. The traditional method for identifying and categorising factors that affect supply or demand is a common sense. However, a more precise pricing model should be developed to reveal, at the initial stage, two integrated factors representing controllable and uncontrollable elements that are capable of affecting prices. Because both integrated factors are completely independent, the sum of their coefficients can only equal one, which is also a common-sense outcome.

Uncontrollable factors always exist in every economic environment. Regarding MPT, such factors contribute to systematic risks if the environment is by itself capable of achieving a significant degree of risk diversification. For example, the global economy is an uncontrollable factor that can affect the operation of a globalised enterprise. For a localised company, local, national and global economies are all system factors that cannot be controlled by this company.

People create social and economic environments in addition to the ecological environment. Because the first and the last one involve noneconomic elements, they can only be most effectively quantified through team work. In contrast, quantifying the economic environment is primarily the responsibility of economists.

\section{Economic Risks}

Apart from time deposits and arbitrage, all economic activities naturally involve various risks. First, the absence of risk implies the impossibility of failure and, hence, a lack of economic problem. (Note 4) Next, human ancestors encountered scarcity and life-threatening risk on a regular basis. Solving such problems began with domesticating certain animals and plants and developed into conquering neighbouring territories. However, after the industrial revolution had accelerated scales of economy, necessities had flooded into disaster, ultimately transformed the original life-threatening risk into the risk of economic failure.

The traditional view of the pursuit of economic growth is flawed. In a two-dimensional risk $(\sigma)$ and return $(E)$ system, unless risk is not a concern, the most crucial economic task is to reduce the risk of failure. In this circumstance, pursuing economic growth cannot be discussed without considering risk. Taking the stock market as an example, a market portfolio, representing optimal portfolio investment, has the largest WINDEX or optimal chance of success in the market to outperform the opportunity cost (Yu, 2012). (Note 5) In contrast, an individual stock can have the highest expected rate of return in the market but its risk of failure is higher than that of the market portfolio; therefore, it cannot be the optimal choice.

The second reason is that the pursuit of economic growth is not meaningful if life-threatening risks emerge after too many external costs incurred. Recently, numerous nations have allowed their expenditures in solving pollution to be listed as an income instead of a cost. This should be treated as a plot for the sake of pursuing only economic growth.

Third, based on MPT, total risk comprises nondiversifiable (or uncontrollable) systematic and diversifiable (or controllable) individual components. By following Adam Smith, numerous economists and scientists have acknowledged that collective conditions become more evident as the physiological and moral characteristics of individuals subside (Bernstein, 2006). As can be implied from Fama (1976), by gradually analysing more participants, system factors eventually become quantifiable. This indicates that excluding system factors that concern particularly economic stability from economic analyses is inexcusable. Moreover, if the goals of economic growth and stability can be achieved simultaneously without any governmental intervention, focusing on only growth is biased.

Finally, in the risk world, only system, instead of individual, factors can be directly observed in the economy; therefore, economics must be inclined towards normative, instead of positive, descriptions and analyses. Furthermore, MPT, which is thus far the only standardised tool for quantifying system factors and analysing risk-related issues in 
economics, involves normative features (Markowitz, 1990). Using the financial market as an example, in which the most crucial and fundamental purpose clearly concerns asset pricing. The primary task is determining the link between the uncertain future return of an asset and its present value. A major breakthrough in this regard was clearly the establishment of CAPM. However, as explained by Yu (2012), within the discounting process, the expected value or rate of return in the numerator is only a first-moment measure and, hence, does not reveal any information of risk as a second-moment measure. Accordingly, no legitimate uncertain discount factor in the positive sense is achieved to address the uncertainty and risk of the numerator. This is why only a normative uncertain discount factor can be applied when performing a discounting task with uncertainty or risk.

\section{Markowitz's Portfolio Theory}

Relation and risk are only static descriptions; neither is directly applicable to formulating risk management strategy. MPT is useful for addressing this problem. For example, a unique function of MPT is solving both the systematic risk portfolio (or the system factor) and the optimal portfolio in resource allocation, representing various environmental definitions of constraint conditions and development opportunities, respectively. (Note 6) In applications, the previous mentioned normative uncertain discount factor must comprise these two portfolios (Yu, 2012).

System factors have previously been neglected academically and institutionally. For example, the deviation of system factors between a localised company and a globalised enterprise can be substantial. Therefore, allowing both companies to compete directly when both have identical development opportunities in the same area but unequal constraint conditions is unfair. Therefore, the government must intervene and establish a basis of fair competition.

If management seeks fairness and justice, the system, instead of individual, factors should be the primary concern. In practice, essential tasks involve first determining the system factor and then breaking through environmental constraints for acquiring better growth opportunities or reducing systematic risk components. Determining the system factor is related to risk diversification, whereas breaking through constraints relates to globalisation.

Although highly valued in the financial market, the optimal portfolio of resource allocation has not received sufficient attention in other markets. Individuals and companies typically lack the necessary understanding and have insufficient power to execute improvement policies concerning this portfolio. Understanding the optimal industrial structure or resource allocation portfolio of a nation is therefore the responsibility of the government, as well as coordinating other sectors, such as education and transportation, to achieve economic development.

Regarding performance evaluation, the optimal portfolio of resource allocation $M$, representing opportunities for development, cannot be neglected. First, the difference in WINDEX between the present condition $P$ and $M$, expressed as $\Delta W_{P}-\Delta W_{M}$, serves as the basis of performance evaluation (Yu, 2014). Next, even if $\Delta W_{P}$ deteriorates, as long as $\Delta W_{P}-\Delta W_{M}$ is improving, a good sign of resisting environmental stress can still be confirmed. Conversely, even if $\Delta W_{P}$ is improving, if $\Delta W_{P}-\Delta W_{M}$ is deteriorating, the conclusion remains negative when opportunities provided by the environment cannot be effectively exploited.

\section{Key Natural Laws in Economics}

The choice between freedom and equity, or between capitalism and socialism, is a point of contention that is rarely compromised among the various schools of economics. Both are equally essential for achieving the national goal of sustainable management and one cannot replace the other.

However, an overzealous commitment to individual rationality has resulted in the global economy developing extremely weak self-control. Consequently, overconsumption and disregard of social rationality have produced a new form of global life-threatening risk.

Galbraith (1960) warned that as soon as short-term consumption can be effectively satisfied, society should focus on social rationality to manage the concern of long-term consumption. Otherwise, people blindly accumulate personal wealth only for self-protection. However, governmental intervention can easily hinder the spirit of freedom and, hence, individual rationality. Determining whether certain natural economic laws allow both individual and social rationality to coexist and function independently without any governmental intervention is crucial.

\subsection{Key Natural Laws in Microeconomics}

According to common sense, all sources of influence can always be divided into two independent categories: controllable and uncontrollable. Once both categories can be represented by an individual and a system factor, 
respectively, the sum of influence from both factors can only be one (Yu, 2012; 2014). This is required for a rigorous pricing model that can conform to common sense.

In econometrics, if a model contains more than one explanatory variable, the relationships among all variables are typically nonlinear. However, if a variable is a system factor, the entire model can be simplified by transforming the nonlinear into a linear relationship and the sum of all coefficients is one (Yu, 2012; 2014). This type of balanced pricing models and their unique features can thus be considered key natural laws in microeconomics.

The proposed balanced pricing models are empirically testable. Using the bivariate asset pricing model, introduced by $\mathrm{Yu}$ (2012), as an example, for a straggler or new-comer in an industry, the coefficient of its controllable variable should be smaller than 0.5 , indicating that it is more easily affected by its environment. (Note 7) In other words, one company must outperform the market to benefit from improved valuation. Similarly, industrial structure can be rigorously studied by examining the same coefficients.

\subsection{Key Natural Laws in Macroeconomics}

Researchers such as Smith have already expressed their opinions on economic development from an evolutionary perspective. "According to the natural course of things, therefore, the greater of the capital of every growing society is, first, directed to agriculture, afterwards to manufactures, and last of all to foreign commerce."(Smith, 1976, p.405) Veblen (1896) subsequently initiated evolutionary economics. Institutional or new institutional economics then emerged. In principle, the various schools agreed that evolutionary order in economics must exist. In addition, Schumpeter (1951) raised his famous concept of innovative destruction and indicated that enough innovators and entrepreneurs must appear to carry one nation's business cycle to a new and higher level. However, no study clearly addressed what the evolutionary order should entail or how the levels of the business cycles would appear.

If key natural laws in macroeconomics actually exist, a nation can draw its own effective economic policies from those laws after fully clarifying its current economic development. Based on this consideration, Yu (2014) introduced the Chinese five elements for explaining the general evolutionary path of economic development.

\subsubsection{Five Elements and the Evolutionary Path of Economic Development}

In the economic sense and based on the interactions of the five elements, the generating cycle progresses from fire to earth, to metal, to water, to wood, and back to fire, indicating the next cycle. In contrast, the overcoming cycle starts from fire to metal, to wood, to earth, to water, and back to fire, indicating the next cycle. Because the five elements are a description of natural laws, they should be capable of describing the general evolutionary path of economic development.

At the very beginning, ancient people relied on luck to survive; this was the stage of fire, or the gathering economy. To avoid life-threatening risks, ancient people exerted their wisdom to tame as many animals and plants as possible and, hence, move into the stage of earth, or the pastoral economy. Subsequently, self-control was gradually established, transforming human into a unique species on the planet, based on their consumption of resources.

Whenever the supply of subsistence goods could not escape from the life-threatening risk, invading neighbouring territories was a common solution. However, once the main economic problem became risk of economic failure, people were forced to determine an effective way of resolving the abundant subsistence goods. An evident solution was to transform those surpluses into societal necessities; hence, people moved into the stage of metal, or the manufacturing economy.

A unique property of the industrial revolution was the rapid expansion of scales of economy. Subsequently, major economic problems had been related to abundance and competition. Immediate and effective solutions had been to exploit markets and raise production capacity for gaining competitiveness. The stage of water began with increasing demand for logistics and financing. Gradually, having reached an extreme extent of globalisation, economic development marginally decreased. Human wisdom was relied on to solve the even serious problems of abundance and competition. New ideas were attempted to reduce risks of economic failure. For example, creating more value-added services based on data-mining customer information, or conducting innovative research and development by acquiring professional expertise to produce more necessities and even luxuries. This is the current state of the world economy; the stage of wood, or the knowledge economy.

Meanwhile, new life-threatening risks have started to emerge as over-consumption and environmental damage gradually destroy the foundation of living. The necessity of using precious resources simply to maintain environmental sustainability is the tragedy of returning to an old problem (Gailbraith, 1960). (Note 8) At present, preliminary innovation comprises researching new energy sources and methods of consuming resources, such as in a 
green or blue economy.

\subsubsection{Five Elements and Markowitz's Portfolio Theory}

If the current economic development of a nation deviates substantially from the evolutionary path and any effort to adjust and return to the right track is too costly, alternatives must be considered. This is how the overcoming interactions of the five elements can be applied for achieving economic development. This type of strategy can also be explained using MPT. This is initiated by linking at least two countries that are complementary to each other in economic development. The task is to make the allied group conform to the normal path of economic development, as elaborated by the five elements.

The information and high-tech industries in India are currently flourishing; hence, the country can use the global knowledge economy to develop its wood stage. However, excessively emphasising information and knowledge development eventually weakens agriculture. Consequently, the risk of food shortage remains. When life-threatening risks and potential economic failure coexist, the Indian government will experience difficulty implementing any effective policy to simultaneously manage both types of risk.

Based on MPT, the solution is to cooperate with another nation or group of nations that are highly heterogeneous to Indian economic development. In other words, the strategy is to combine an ally or allies that offer a high level of agricultural technology, in addition to sufficient agricultural surpluses, but possess a marginally developed or relatively weak knowledge industry. (Note9)

\subsubsection{Five Elements of Next Cycle}

The first cycle of the five elements is currently nearing its end. The preliminary suggestion of this study is presented as follows. First, based on the Chinese Yin-Yang Doctrine, the nature of the current five element cycle is defined as Yang: material, creation, and destruction. Therefore, the nature of the next five element cycle must be Yin: spirit, suppression, and repair.

Because the present life-threatening risk is caused by environmental damages, the natural solution is immediately restoring the natural order of the ecological environment; humanity can thereby proceed to the next new earth stage. The stages of metal and water will naturally follow. In these stages, the primary task will be repairing the economic environment. Subsequently, the social environment will require repair and civilization will enter the wood stage.

The general virtue to be applied in the new fire stage for effectively attracting innovative ideas to solve life-threatening risks is manners. Subsequently, those general virtues are faith for the earth stage, trust for the metal stage, wisdom for the water stage and benevolence for the wood stage. This is because virtue, instead of intelligence, will become the most crucial means for accomplishing the task of repair in the next five-element cycle.

Nations that have inflicted less damage on their environments will have a considerably lighter burden restoring its sustainability. This can be inferred from the Chinese Doctrine of the Mean: whichever countries develop slowly during the first cycle can move faster during the second cycle if their environmental damages from the first cycle are marginal. Meanwhile, a new form of life-threatening risk will emerge and serve as the driving force to continually move civilisation forward.

Life-threatening risks that will accumulate during the second cycle of the five elements will most likely originate from religion. Only the risk of religious wars can threat civilisation during this second cycle. Solutions must rely on an even higher intelligence than that available today.

\section{Conclusion}

Economics can be more practical if relationship and risk, as well as scarcity and abundance, are considered key elements in economic analyses. Economic history has thus far been as a process of reducing risks of failure in life and business. A life-threatening risk that was considered to be solved is now reappearing. Furthermore, policies addressing life-threatening and economic failure risks are typically contradictory, resulting in difficulty formulating effective national policies for economic development.

By applying relations and risks through MPT, the long and difficult task of introducing an appropriate economic environment or, particularly, a system factor into a balanced pricing model can become a reality. Accordingly, both individual and social rationality can function independently and a strong balancing effect can be established without any governmental intervention in the pricing model. The rationality of the global economy can also be expected to resume on a micro scale.

Although the global economy seems excessively damaged by individual rationality, the natural order is still in 
progress. This is clear after examining the key natural laws of macroeconomics suggested in this study. Although pitfalls include the emergence of a new life-threatening risk, if people can use wisdom as usual and apply general virtues as the primary means, they can still progress naturally to the next cycle of global economic development illustrated by the five elements. However, certain tasks still need to be achieved as soon as possible, such as establishing balanced pricing models that conform to the key natural laws in microeconomics, as suggested in this study, to reduce damage to the environment.

By inspecting the evolution of the global economy, reducing life-threatening risk and economic failure is the driving force behind breaking through the cycle of economic development. However, when the goal of sustainability is concerned, freedom must be the objective. In other words, human must be free from risks of moral danger and economic failure. Sen (2000) certainly believed that wealth is not the goodness that we pursue; it is needed for other reasons. Nature highlights diversification; however, seemingly, only human can be unified by a general code of ethics.

The key natural laws of economy reveal that the global economy is still progressing naturally. This indicates that economics should be optimistic by nature. Although MPT can already quantify physical risk relations in the economic world, measurement of chemical relationships remains no standard rules. Progress is required for it to become a standardised tool and analysis framework in the future.

\section{References}

Bernstein, P. (2006). Against the Gods: The Remarkable Story of Risk. (in Chinese). Taipei: Businessweek.

Cheng, Y. (2002). The WINDEX View of Stock Investment, (in Chinese). Master thesis of Department of Economics, Ming-Chuang University, Taiwan, ROC.

Fama, E. (1976). Foundations of Finance. New York: Basic.

Galbraith, K. (1960). The Affluent Society. New York: Houghton Mifflin.

Kant, I. (1997). Critique of Pure Reason, translated and edited by P. Guyer and A W. Wook. Cambridge, UK: Cambridge University Press.

Markowitz, H. M. (1990). Is normative portfolio theory dead?. Journal of Economics and Business, 42(2), 95-98.

Robbins L. (1952). An Essay on the Nature and Significance of Economic Science (2 ${ }^{\text {nd }}$ ed.). London: Macmillan.

Schumpeter, J. A. (1951). The Theory of Economic Development, translated by R. Opie. Cambridge, Mass.: Harvard University Press.

Sedlacek, T. (2013). Economics of Good and Evil: The Quest for Economic Meaning from Gilgamesh to Wall Street, (in Chinese). New-Pei, Taiwan: Streamer.

Sen, A. (2000). On Ethics and Economics. (in Chinese), Taipei: Linking.

Smith, A. (1976). The Wealth of Nations, edited by E. Cannan. Chicago: University of Chicago Press.

Yu, Y. (2012). The asset pricing system. Modern Economy, 3(5), 473-480.

Yu, Y. (2014). A more practical method for explaining equilibrium. Research in World Economy, 5(1), 88-98.

\section{Notes}

Note 1. "Instead of regarding the economic system as a gigantic machine for turning out an aggregate product and proceeding to enquire what causes make this product greater or less, and in what proportions this product is divided, we regard it as a series of interdependent but conceptually discrete relationships between men and economic goods" (Robbins, 1952, p.68). Kant (1997, pp.188,189) also once said that, "everything in our cognition that belongs to intuition (with the exception, therefore, to the feeling of pleasure and displeasure and the will, which are not cognitions at all) contains nothing but mere relations."

Note 2. The supposed imperfection implies all external costs incurred by resource consumption.

Note 3. "In Western economics, the values of which it takes account are valuations of individuals." (Robbins, 1952, p.91)

Note 4. Sedlacek (2013, p.147) once quoted Martha Nussbaum, mentioning that Socrates believed that the entire civilisation and history of human beings is simply the story of gradually controlling accidents.

Note 5. Because risk and the expected rate of return have distinct features, legitimately merging them requires 
applying division. This is the coefficient of variance in statistics if the outcome is $\sigma / E$; otherwise, it can be interpreted as the expected rate of return that can be obtained on average by bearing one unit of total risk if the outcome is $E / \sigma$. By realistically considering the opportunity cost, $E / \sigma$ can be revised to become $\left(E-r_{f}\right) / \sigma$ which, in turn, coincides with the Sharpe ratio. Next, per unit total risk $\sigma$ for various assets are heterogeneous products in the risk system and, hence, cannot be mutually compared. Based on the assumption of lognormal distribution, $\left(E-r_{f}\right) / \sigma$ can be transformed into a term for calculating accumulated probabilities, $\mathrm{N}\left(\left(E-r_{f}\right) / \sigma\right)$, and is named "WINDEX" (Cheng, 2002). The reason that the per unit total risk can differ is that, in the risk system, the ratio between individual and systematic risk components within per unit total risk can differ and the content of individual risk component can vary widely among various assets (Yu, 2012).

Note 6. The premise is that the environment is itself already capable of achieving a substantial degree of risk diversification.

Note 7. In contrast, this coefficient for a monopolist must be 1.

Note 8. "To have failed to solve the problem of producing goods would have been to continue man in his oldest and most grievous misfortune. But to fail to proceed thence to the next task, would be fully as tragic." (Gailbraith, 1960, p.356)

Note 9. The opinion of introducing foreign help to accelerate the development of domestic agriculture was mentioned by Smith (1976, pp.405, 406). "But though this natural order of things must have taken place in some degree in every such society, it has, in all the modern states of Europe, been, in many respects, entirely inverted. The foreign commerce of some of their cities has introduced all their finer manufactures or such as were fit for distant sale; and manufactures and foreign commerce together, have given birth to the principal improvements of agriculture." 